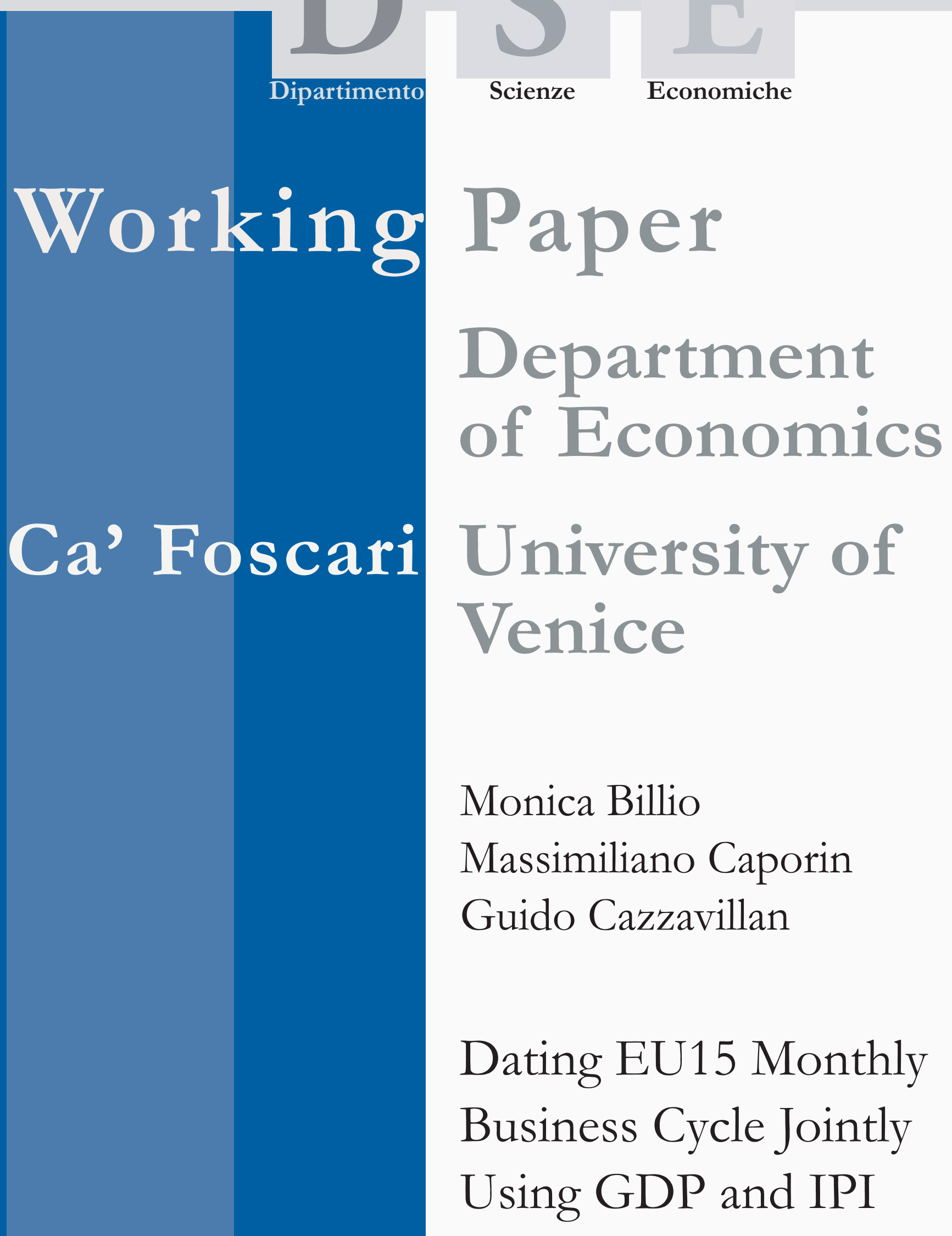




\title{
Dating EU15 Monthly Business Cycle Jointly Using GDP and IPI
}

\author{
Monica Billio \\ University of Venice and SSAV, Scuola Studi Avanzati in Venezia
}

\section{Massimiliano Caporin}

University of Padova

\section{Guido Cazzavillan}

University of Venice

\begin{abstract}
This paper aims at the production of a chronology for the EU15 business cycle by comparing parametric and non-parametric procedures on monthly and quarterly data as well in a combined approach. The main innovation is the joint use of the monthly series for the EU15 Gross Domestic Product (GDP) and the EU15 Industrial Production Index (IPI) from 1970 to 2003. The monthly IPI and the quarterly GDP at the EU15 level have been reconstructed starting from the available national series. The monthly GDP has then been computed using temporal disaggregation techniques. The obtained chronology is directly comparable to ones produced by several authors for the euro area.
\end{abstract}

\section{Keywords}

Business cycle, Chronology, Historical reconstruction, Monthly GDP

\section{JEL Codes}

E32, C82

\author{
Address for correspondence: \\ Monica Billio \\ Department of Economics \\ Ca' Foscari University of Venice \\ Cannaregio 873, Fondamenta S.Giobbe \\ 30121 Venezia - Italy \\ Phone: (++39) 0412349170 \\ Fax: (++39) 0412349176 \\ e-mail: billio@unive.it
}

This Working Paper is published under the auspices of the Department of Economics of the Ca' Foscari University of Venice. Opinions expressed herein are those of the authors and not those of the Department. The Working Paper series is designed to divulge preliminary or incomplete work, circulated to favour discussion and comments. Citation of this paper should consider its provisional character. 


\section{Introduction}

From the beginning of macroeconomics, investigators have been fascinated by patterns in graphs of data on production, employment and prices and such patterns were termed cycles. Many theories have been advanced to explain these cycles and amongst academics, evidence on the nature of cycles has changed from a graphical orientation towards quantitative measures.

The business cycle is a pattern seen in a series taken to represent the "aggregate economic activity", thus the business cycle can be defined as a broadly-based movement of economic variables in a sequentially oscillatory manner. The detection and description of any cycle is accomplished by first isolating turning points in the series (defined as peaks or trough in the economic cycle) after which those dates are used to mark off periods of expansions and contractions. Location of turning points is the dating exercise.

There is a long tradition among macroeconomists, exemplified by the work of Burns and Mitchell (1946), of characterizing the U.S. aggregate business cycle as a series of distinct phases. This tradition is carried on today by the National Bureau of Economic Research's (NBER) Business Cycle Dating Committee.

As well known, the NBER Business Cycle Dating Committee provides an official dating of peaks and troughs for the United States business cycle. Differently, at the moment in the European Community, there is no official cycle chronology, ${ }^{1}$ while economic experts and practitioners generally emphasize the need for such a chronology. In fact, the cycle reference dates can be considered as benchmarks in many empirical studies, starting from real time business cycle detection to policy evaluation analysis. As an example, the chronology may help in comparing the cycles among European countries or may evidence relationships between a country's cycle and its main economic aggregates or, further, among the cyclical oscillations of the main economic aggregates (different sectors may react in different ways to a global macroeconomic movement).

The main contribution given by a chronology resides in the identification of a reference cycle dating for an economic aggregate, a given country or an economic area. Furthermore, a reference cycle would be used, in an empirical perspective, to classify economic aggregates, indicators and structural business statistics in leading, coincident or lagging (accordingly to their advance with respect to the reference cycle). Finally, the availability of an official chronology allows the validation of real-time cycle phase detection and forecast, a policy evaluation-related need.

Necessarily, the chronology construction can be only made ex post. The fundamental principle is thus the accuracy of the relevant dates, favoured to timeliness. This lack of timeliness could make the dating less relevant for policy evaluations. On a different perspective, central banks and national governments are concerned with indicators that anticipate a growth weakening or the beginning of a recession; in fact, this will allow an adequate policy implementation. In this case, timeliness becomes more relevant. Both

1 A chronology does not exist for the enlarged European Community as a whole, nor for the former EU15, nor for the euro area (EU12). 
issues are connected with the real-time detection of the business cycle. However, the implementation of a real-time detection methodology needs a validation analysis which must be first based on a reference chronology.

When performing a cycle dating exercise several questions arise. First of all, the economic cycle must be clearly defined. The literature recognizes two broad definitions of the cycle, the so-called classical or business cycle and the growth or deviation cycle. The first refers to oscillations in the levels of macroeconomic series, while the second refers to movements in deviation from their long-term trend. The business cycle has attracted the main interest in the literature (as an example, the NBER produces a reference chronology only for the business cycle). However, in early post-war decades, especially in Western Europe, growth was relatively persistent and absolute declines in output were comparatively rare; the growth cycle then seemed to be of more analytical value. In more recent decades, there have been a number of instances of absolute decline in output, and popular description at any rate has focussed more on the classical cycle. In addition, the concern that detrending methods can affect the information content of the series in unwanted ways has reinforced the case for examining the classical cycle. We also follow this line of research mainly focusing on the classical cycle, whether using the growth cycle in preliminary analysis for comparison purposes.

A further point to consider, deals with the methods to be used for the turning point chronology construction. One popular approach is the algorithm given in Bry and Boschan (1971), which is designed to identify turning points between periods of expansion and contraction in the level of a time-series. The Bry and Boschan procedure identifies local minima and maxima in the series, enforcing that business cycle phases are of some minimum length. An alternative and newer business cycle dating method is the Markov regime-switching model of Hamilton (1989). Hamilton specifies a parametric time-series model in which the mean growth rate switches between high and low growth regimes. The timing of these regimes and the within-regime growth rates are then estimated from the data. Both the Bry and Boschan and Hamilton approaches have been shown to produce a reasonably accurate replication of the NBER chronology when applied to aggregate data. The Bry and Boschan algorithm has the virtue of being very transparent, as it takes the form of a simple data-driven rule for dating turning points. However, for state-level data, the Hamilton approach has the advantage over the Bry and Boschan algorithm of not requiring that recessions be absolute declines in economic activity.

Clearly, different approaches may provide distinct reference dates as evidenced by a strand of literature focusing on this specific topic. However, we must note that this literature is specific to the US case, while references to the European case are limited by the unavailability of an official chronology. In the following, we will consider both nonparametric approaches based on the Bry and Boschan procedure and parametric models belonging to the Markov-switching class (Hamilton, 1989, 1990, and Krolzig, 1997).

From a practical point of view, when dealing with a cycle dating exercise, some problems related to data emerge too. They concern data availability, data revision and the aggregation process. 
First of all, a very relevant problem for the EU15 area is the data availability. In fact, EU15 series are generally available only from mid 80's. In this paper we will estimate, within a regression framework, EU15 time series from 1970.

Concerning data revision, clearly the dating reaches its optimal reliability with the last revised data. However, the final data revision may require a quite long delay, in particular for national accounts series. The GDP series can be continuously revised using new available indicators and surveys or for methodological advancements (well-known examples are the recent national accounts revision in Japan, the Fischer chain-linked price series for the US and the introduction of chain-linked GDP volumes for the euro area ${ }^{2}$ ). To reduce the revision process drawbacks we may consider different series, but in this case, the availability and the homogeneity of these series over a long period of time are necessary to provide consistent and reliable dating through time. As regards the euro area, the availability of long historical time series is a serious problem, in spite of Eurostat efforts to provide such data sets. At the moment new chained-linked series for the euro area are available only since 1995. Moreover, differently from the United States, for EU15 the sales series is not available and the employment series seems to have less importance because of its strong persistence.

This revision issue has been addressed in the United States; however their experience on the relationship between the dating and revision processes cannot be extended to the European case given the different data revision schemes. European GDP series are revised quarterly and depend on the revisions of national series and on the release of data by member countries. ${ }^{3}$ Differently, the IPI is subject to a "continuous" revision scheme: the available series is adjusted any time a new country provides either a new data point or a revision of past values of the index. ${ }^{4}$ Therefore, revisions may play a different role on the dating depending on the type of reference data that are considered or on the revision scheme that affects the reference series.

As the main objective of the paper is the production of a chronology for the EU15 considering series at different frequencies (compulsory choice given the quarterly frequency of the GDP), we will not address the revision issue, leaving it for future studies.

Finally, when dealing with series produced by an aggregation process (in that case of national corresponding series) we face a problem of choice between two possible approaches: date the cycle over the aggregated series, considering the EU15 as a whole economy (direct approach) or, alternatively, take advantage of the available disaggregated series and their chronologies (indirect approach). In the former approach, we presume the existence of a unique common cycle covering all EU15 countries, while in the indirect approach we face different problems. In that case, we should first analyse each national series extracting the reference chronology, then verify the cycle synchronisation and

At the end of 2005, new chain-linked GDP volumes for the Euro zone were published for the first time by Eurostat. Revisions were sufficiently small in order to have no impact on the dating of the business cycle.

The first release of GDP EU15 series replaces unavailable country data with an estimate made internally by Eurostat. As for the GDP, for the first release missing countries are estimated. 
diffusion over countries. In the end, if there is a sufficient synchronisation, we should aggregate the national results by some method to produce the EU15 chronology. This latter process includes a further problem, related to the parametric model specification: the choice between univariate and multivariate specifications clearly will depend on the chosen approach.

In this paper we will focus on a direct approach, given the different data availability over the EU15 countries, which clearly creates additional problem if dealing with an indirect approach, ${ }^{5}$ since the study of the business cycle needs a larger sample than several years. Some support of our choice comes also from the recent work by Camacho et al. (2005). They examine some stylized facts about the European business cycles and their evolution over time. Their analysis evidences a cluster which contains the majority of the EU15 countries ${ }^{6}$.

From a methodological point of view, we present an extension of existing approaches by considering a bivariate model that jointly use the monthly IPI and monthly GDP series. Since not officially available, the monthly GDP has been produced by a Denton disaggregation approach (Denton, 1971). Several other and more advanced disaggregation procedures exist but they require an available indicator, which most of the times is the IPI. Using the IPI as indicator may however induce the monthly reconstructed GDP to follow the IPI cycle. We thus use the Denton approach and show that the quarterly GDP series and the IPI probably share a common cycle by mean of a concordance analysis based on univariate modelling.

A final comment refers to our choice of focusing on the EU15 instead of the euro area. The answer is rather simple: we prefer to not exclude the UK. ${ }^{7}$ This choice is somewhat different with respect to the available literature that generally focuses on the euro area. However, to focus on the euro area only for the existence of a common currency is somewhat restrictive. In fact, historically, UK joined the European Community in the early 70 's and contributed to the principal steps leading to the Maastricht treaty. Then, excluding UK, one of the largest 5 European countries, because they do not decided to adopt the Euro currency seems inappropriate. EU15 may be considered as an economic area, in fact recent studies evidence (see for example Artis, 2003) that there is a positive correlation between the UK cycle and the cycle in other European countries over an extended period; the same is true for the correlation of identified demand shocks, at least when only supply and demand shocks are identified. ${ }^{8}$ See also Artis et al. (2004) and Kaufmann (2003) for an inclusion of the UK in the study of the European business cycle.

5

Research by the authors is currently under way in evaluating an indirect approach.

There is also a significant literature on the analyses of the euro area business cycle with a direct approach. See for example Artis, Marcellino and Proietti (2003), Mcadam (2003), Anas et al. (2007).

The use of European Community series whether relevant for actual policy issues has not been considered given the serious lack of data for the Eastern Europe new member states.

Artis (2003) also analysed whether there is or has been a 'UK idiosyncrasy' and by this term observers have meant to grant that there is, or has been, something a bit different about the UK business cycle and the UK economy's experience of shocks. 
The plan of the paper is as follows: Section 2 deals with the data problem, describing the approach used in constructing the database and presenting the estimated series; Section 3 considers the nonparametric approaches while Section 4 the parametric one; Section 5 focuses on a bivariate model that jointly considers GDP and IPI series; Section 6 concludes.

\section{$2 \quad$ Dataset Reconstruction}

To provide a chronology of the business cycle, we need data supplying a good measure of the EU15 economic activity and this data should cover a relevant time-period. Traditionally, dating exercises for Europe use the quarterly GDP series or Industrial Production Indices as a reference database. Unfortunately, the available EU15 series cover a too short period, starting from January 1985 (Industrial Production) or from the first quarter of 1991 (National Accounts series).

Necessarily, the first step required to provide a useful chronology (which should cover the longest possible time period) is to evaluate if it is possible to extend the relevant variables in the past in order to obtain sufficiently long series. We thus consider a retropolation or back-recalculation approach, which aims to estimate the past values of a relevant series on the basis of the present available information. A general discussion of the back-calculation problem and of the available approaches can be found in Caporin and Sartore (2006).

For our purposes, the relevant series are the EU15 Industrial Production Index ${ }^{9}$ and the EU15 Gross Domestic Product. ${ }^{10}$ Given the lack of aggregated EU15 data we chose to extensively search in available databases for series measuring the relevant variables at the national levels, from which the aggregated series would then be estimated. The Eurostat and OECD databases have been scanned, as well as DataStream and the National Statistical Institutes (NSI) databases. On the basis of the obtained information we evaluated that the maximum length of a possible reconstruction can start in 1970. With our approach, in a first step we focus on the back-recalculation of national series using various data: NACE disaggregated production indices on different base years; NSI series; historical Eurostat series. Afterwards, EU15 series is estimated using a partial indirect approach, i.e. by aggregation of the obtained retropolated national series and retropolation on them. The retropolation considers working day adjusted series, while the seasonal adjustment is analysed in a second step.

Before shortly presenting the adopted methodological approach, some word of caution should be given. Data availability represents a fundamental step for any retropolation exercise as well as for the successive analysis of the gross database; in fact, several errors

\footnotetext{
9 Total Industry excluding construction, NACE rev. 1 sectors C, D and E (Mining and Quarries, Manufacture and Energy). Seasonally adjusted and working day adjusted series in 2000 basis year. adjusted series.
} 
could affect the data: missing observations, compilation outliers, typing errors or not reported basis changes.

The basic idea behind the retropolation of a time series is the possibility of finding a related indicator which can be in turn a proxy variable, a partially available variable (i.e. for EU15 it may be EU10 or a smaller subset of European countries), the relevant variable measured at a different frequency (i.e. for a monthly series some previous quarterly values can be available). In the presence of a related indicator, three possible general situations may be considered: a) the related indicator is at the same frequency as the relevant variable we want to retropolate; b) the indicator measures the relevant variable at a different, lower, frequency; c) there are both an available indicator and a lower frequency series.

In the second case, which will not be considered here, a temporal disaggregation technique should be considered (see Di Fonzo, 2003b). In the third case, the methodology of point a) should be integrated or followed by a benchmarking process or by a constrained temporal disaggregation (see Di Fonzo, 2003a). Finally, in the case a), the retropolation is made within a regression framework, according to the following general setup.

If we consider a series $x_{t} t=0, \ldots T$, that has to be back-recalculated in the range $(-M,-1)$ and assume the availability of a related indicator $y_{t}$ for the range $(-M, L)$ with $L \leq T$, the retropolation of $x_{t}$ is made on the basis of the coefficients estimated in the following regression:

$$
\Delta \ln \left(x_{1}\right)=\beta_{0}+\beta_{1} \Delta \ln \left(y_{t}\right)+\sum_{j=1}^{S-1} \beta_{j+1} \delta_{j}+\varepsilon_{t} \quad t=0, \ldots . L
$$

where $\left(\delta_{j}, j=1 \ldots S-1\right)$ is a set of the seasonal dummies. It can be noted that the estimation is performed on the logarithmic growth rates without any explicit dynamic, even if the error term can be generalised to include ARMA terms. An explicit dynamic (of the growth rates) is not included since it will prevent any back-recalculation; in fact, the inclusion of autoregressive (AR) terms will provide an explosive pattern whether moving average (MA) terms become useless. ${ }^{11}$ Differently, we could consider a time series reversion which enables using the dynamics of the series. However, as pointed out by Ramsey and Rothman (1996), a series is reversible if it possesses a symmetry property. It is well known that the business cycle is asymmetric (see inter alia Neftçi, 1984, Hamilton, 1989, Sichel, 1993, Acemoglu and Scott, 1997) and this rules out time series reversibility. The undemanding representation (1) combines flexibility, easiness of estimation and interpretation as pointed out in Caporin and Sartore (2006).

Once the coefficients of equation (1) have been estimated, the retropolated values of $x_{t}$ are obtained by the following formulae:

11 Assume that $x_{t}$ follows a simple AR(1) process: $x_{t}=\phi x_{t-1}+\varepsilon_{t}$. If we want to back-calculate $x_{t}$ using its own dynamic, we should write $x_{t-1}=\phi^{-1} x_{1}-\varepsilon_{t}$; the process become non-stationary with an explosive pattern. Differently, for an MA(1) we have $x_{t}=\theta \varepsilon_{t-1}+\varepsilon_{t}$ and past values of $x_{t}$ are functions of unavailable innovations. 


$$
\begin{aligned}
& \Delta \ln \left(\hat{x}_{t}\right)=\hat{z}_{t}=\hat{\beta}_{0}+\hat{\beta}_{1} \Delta \ln \left(y_{t}\right)+\sum_{j=1}^{S-1} \hat{\beta}_{j+t} \delta_{j} \quad t=-M+1, \ldots,-1 \\
& \hat{x}_{t-1}=\hat{x}_{t} \exp \left(\hat{z}_{t}\right)^{-1} \quad t=-M+1, \ldots, 0 \quad \hat{x}_{0}=x_{0} \quad \hat{z}_{0}=\Delta \ln \left(x_{0}\right)
\end{aligned}
$$

As already mentioned, after the search for the available information we first backrecalculated the EU15 national series of the Industrial Production Index and of the Gross Domestic Product and then aggregated these series and retropolated the EU15 series on them The choice of using such a partial indirect approach (i.e. estimating national series and then the aggregate) is motivated by the fact that the direct retropolation of the EU15 series was not possible given the huge lack of data. The approach is slightly different for the two series considered, as described in the following paragraphs.

\subsection{IPI reconstruction}

We reconstructed the national series on the basis of the available information obtained from different databases reporting European countries production indices. We obtained the temporal coverage reported in Table 1. By using of the national series we calculated a set of European aggregates as a result of a weighted average of them. The weights have been obtained from the Eurostat NewCronos database and represent the weight of each EU15 country in the estimation of the Total EU15 IPI. For the sake of exposition we report the weights in Table 2. The geographical coverage and the ranges of the aggregated series are indicated in Table 3.

Table 1 Industrial Production Index ${ }^{12}$

\begin{tabular}{lcclcc}
\hline \multirow{2}{*}{ Country } & \multicolumn{2}{c}{ Range* } & \multicolumn{2}{c}{ Range* } \\
& Official** & Retropolated & & Official** & Retropolated \\
\hline Austria & M01/1996 & M01/1970 & Italy & M01/1990 & M01/1970 \\
Belgium & M01/1970 & $(1)$ & Luxembourg & M01/1970 & $(1)$ \\
Denmark & M01/1985 & $(2)$ & The Netherlands & M01/1970 & $(1)$ \\
Finland & M01/1990 & M01/1985 & Portugal & M01/1990 & M01/1970 \\
France & M01/1990 & M01/1970 & Spain & M01/1980 & M01/1970 \\
Germany & M01/1978 & M01/1970 & Sweden & M01/1990 & $(2)$ \\
Greece & M10/1995 & M01/1977 & United Kingdom & M01/1986 & M01/1970 \\
Ireland & M01/1980 & M07/1975 & EU15 & M01/1986 & M01/1970 \\
\hline$*$ & Starting period: month and year. & & (1) & No need for any back-recalculation. & \\
$* *$ & Source: Eurostat NewCronos database. & (2) $\quad$ Retropolation was not possible due to lack of data. \\
\hline
\end{tabular}

12 See footnote 10. 
Table 2 Industrial Production Index - country weights - 2000 base year

\begin{tabular}{llllll}
\hline Country & Weight & Country & Weight & Country & Weight \\
\hline Austria & 2.6 & Germany & 26.5 & The Netherlands & 4.5 \\
Belgium & 3.0 & Greece & 0.9 & Portugal & 1.4 \\
Denmark & 1.9 & Ireland & 1.9 & Spain & 7.7 \\
Finland & 1.9 & Italy & 13.5 & Sweden & 3.1 \\
France & 14.2 & Luxembourg & 0.2 & United Kingdom & 17.7 \\
\hline
\end{tabular}

Table 3 Aggregated IPI series

\begin{tabular}{lll}
\hline Series & Geographical coverage & Available from \\
\hline EU10 & $\begin{array}{l}\text { Austria, Belgium, France, Germane, Italy, Luxembourg, } \\
\text { The Netherlands, Portugal, Spain and United Kingdom }\end{array}$ & January 1970 \\
EU11 & EU10 + Ireland & July 1975 \\
EU12 & EU11 + Greece & January 1977 \\
EU14 & EU12 + Finland and Denmark & January 1985 \\
EU15 & EU14 retropolated & January 1970 \\
\hline
\end{tabular}

We thus considered any lower level aggregate (i.e. EU10 for EU11, EU11 for EU12...) as a related indicator for the retropolation of the upper level aggregate. In this step we just made a repeated use of the regression approach described above. The final outcome of this procedure is a EU15 IPI series starting from January 1970, which is reported in Figure 1. Each regression model was specified according to equation (1) and we checked coefficient stability before producing the relevant back-forecasts.

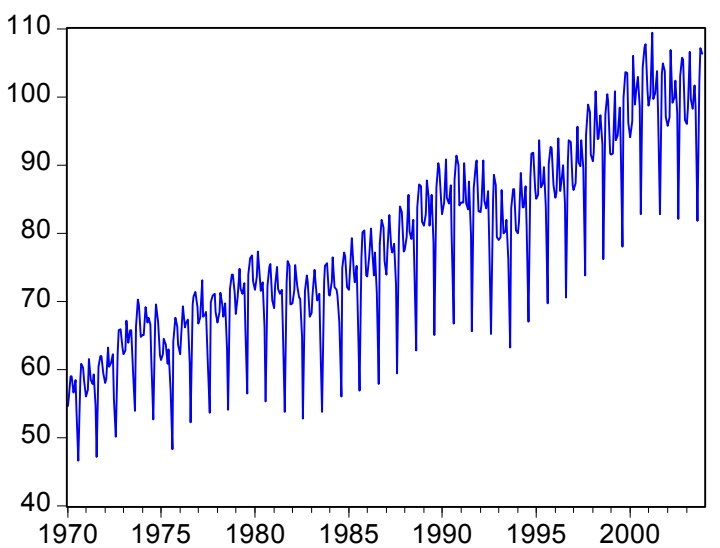

Figure 1: Retropolated EU15 IPI

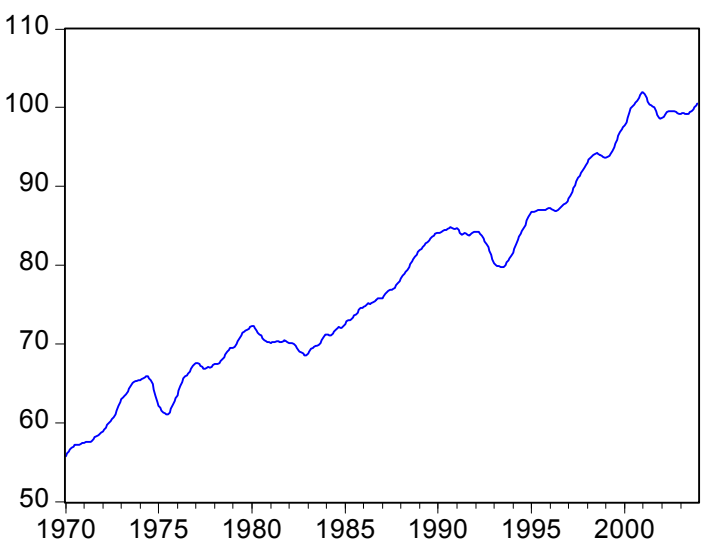

Figure 2: EU15 IPI - Trend-Cycle 


\section{$2.2 \quad$ GDP reconstruction}

The backward estimation of the GDP series was more problematic since the available information is very limited for many countries and not available at all in some cases (see Table 4 for the coverage at the quarterly level). However, both quarterly and annual series are available, the second for longer period and most of the times they go back to 1970 . Given the available data we considered a retropolation of both quarterly and annual series for the EU15 GDP.

Table 4 Gross Domestic Product ${ }^{13}$

\begin{tabular}{lcclcc}
\hline Country & \multicolumn{2}{c}{ Range* } & Country & \multicolumn{2}{c}{ Range* } \\
& Official** & Retropolated & & Official** & Retropolated \\
\hline Austria & Q1/1988 & Q1/1970 & Italy & Q1/1990 & $(1)$ \\
Belgium & Q1/1980 & $(2)$ & Luxembourg & N.A. & $(2)$ \\
Denmark & Q1/1977 & $(2)$ & The Netherlands & Q1/1977 & $(2)$ \\
Finland & Q1/1975 & $(2)$ & Portugal & N.A. & $(2)$ \\
France & Q1/1978 & Q1/1970 & Spain & Q1/1980 & Q1/1970 \\
Germany & Q1/1991 & Q1/1970 & Sweden & Q1/1980 & $(2)$ \\
Greece & N.A. & $(2)$ & United Kingdom & Q1/1970 & $(1)$ \\
Ireland & M01/1980 & $(2)$ & EU15 & Q1/1991 & Q1/1970 \\
\hline$*$ & Starting period: month and year. & & (1) & No need for any back-recalculation. & \\
$* * \quad$ Eurostat NewCronos database. & & (2) & Retropolation was not possible due to lack of data. \\
\hline
\end{tabular}

At the annual level, all national GDP series have been retropolated back to 1970 and the EU15 GDP was derived by direct aggregation of national series. Moreover, we considered the annual GDP series as a benchmark since it was obtained using a very large coverage. Differently, at the quarterly level, the backward estimation of the EU15 series mirrors the procedure used for the IPI: from national series we derived by sum the following aggregates: ${ }^{14}$

14 Ireland is not considered since its coverage is shorter than the actual available EU15 series. 
Table 5 Aggregated GDP series

\begin{tabular}{lll}
\hline Series & Geographical Coverage & Available from \\
\hline EU6 & Austria, France, Germany, Italy, Spain and UK & first quarter 1970 \\
EU9 & EU6 + Finland, The Netherlands and Denmark & first quarter 1977 \\
EU11 & EU9 + Belgium and Sweden & first quarter 1980 \\
EU15 & EU11 + Greece, Ireland, Luxembourg and Portugal & first quarter 1991 \\
\hline
\end{tabular}

The successive step was the estimation of the EU15 GDP using equations (1) to (3). At this point we had two estimated series for the EU15 GDP: at the annual level and at the quarterly level. The final step was the adjustment of the quarterly series imposing the constraint of temporal aggregation: the sum of quarterly data must give the annual value. In this step, we considered the annual series as the benchmark. We made the adjustment by a dynamic temporal disaggregation approach (using the Chow-Lin approach, 1976) by considering the quarterly EU15 GDP as an indicator. The final series is reported in Figure 3. As with the IPI series, the regression models is described in equation (1) and the estimated coefficients are tested for stability over the sample period.

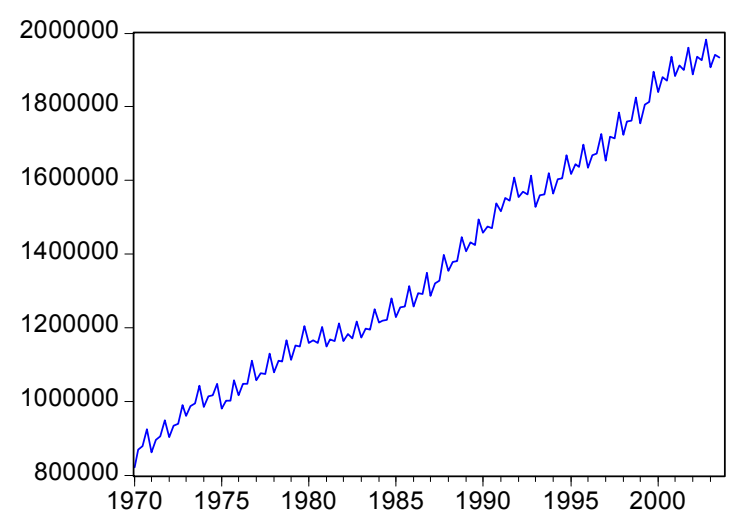

Figure 3: EU15 GDP - retropolated

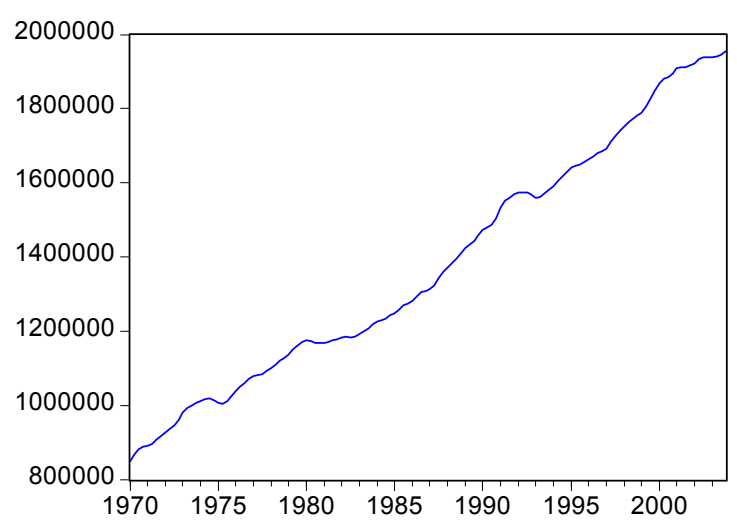

Figure 4: EU15 GDP - Trend-Cycle

\subsection{Seasonal adjustment}

To remove the seasonal component from national and EU15 series we decided to apply the TRAMO-SEATS routines allowing the detection of both additive outliers and transitory shocks. Level shifts are not included since we retain they may affect the turning point detection. The final seasonally adjusted series are reported in Figure 2 and Figure 4 (Trend-Cycle series).

15 The series of Finland starts in 1975 but its weight over the EU15 is limited and we preferred to skip the creation of a EU7 aggregate close to the EU6 for a couple of years; by this way we also reduce the effects of estimation errors. 


\section{$2.4 \quad$ Notes and comments}

It is important to underline that the proposed retropolation and dating approaches may suffer for some drawbacks. First, we implicitly assume that the EU15 countries constitute an economic area from 1970 onward. As mentioned before, there is some evidence on cycle similarities (see Artis, 2003, and Camacho et al. 2005). However, our main purpose is to propose a possible alternative approach that tries to combine monthly and quarterly series. This approach could clearly be extended and applied to national series and thus for a cycle synchronization study.

Furthermore, the use of fixed base weights for the aggregation back to 1970 may introduce distortions in the analysis. In fact, there is no reason for presuming that current weights can be safely applied for the entire available sample. The problem of aggregation is also more difficult when exchange rates are pone to change: in these circumstances there is no "perfect" method of aggregation. However, the current Eurostat practice for the compilation of European aggregates regarding the Principal European Economic Indicators (expressed as index numbers) states that weights should be referred to the base year of the index, and thus fixed for the entire available sample. This may not be the preferred choice, but we prefer to provide data comparable to the actual official European aggregates. This approach is clearly not optimal, given that the aggregation weights are revised every five years and this possibly affects the aggregated growth rates. Anyhow, our purpose is to date the cycle using European aggregates, and in order to be comparable with Eurostat and European Central Bank analysis we have to use series produced following Eurostat standards. A different and more correct approach should consider the inclusion of chainlinking in all indicators (a practice which is under development for GDP).

Finally, we stress that the approach used in the back-recalculation is coherent with Eurostat retropolation activities and procedures (fully described in Caporin and Sartore, 2006) it represents a simplified version of it.

\section{$3 \quad$ Non-parametric Dating}

Once the relevant series have been reconstructed a first turning point analysis can be tackled with a non-parametric approach. We considered the algorithm suggested by Bry and Boschan (1971): their approach, as all standard non-parametric dating methodologies, analyses a series identifying the turning points using rules as follows:
i) There is a peak at $t$ if:
$\left\{y_{t}>y_{t-k}, y_{t}>y_{t+k}, k=1, \ldots, M\right\}$
ii) There is a trough at $t$ if:
$\left\{y_{t}<y_{t-k}, y_{t}<y_{t+k}, k=1, \ldots, M\right\}$

where $M$ is set to 5 for monthly series and to 2 for quarterly series. These rules define a preliminary dating which must then be reconsidered to guarantee some basic characteristics, i.e.:

- peaks and troughs must alternate; 
- there is a minimum duration of 6 months or 2 quarters (both for peak-to-trough and trough-to-peak durations);

- peaks and troughs within six months from the first and last observation should be disregarded;

- a whole cycle must cover at least 15 months.

Other rules and properties are used to verify the dating; they can be recovered in the cited work.

In our analysis, we considered the dating of the EU15 Industrial Production Index and the Gross Domestic Product as reconstructed in the previous Section. With the non parametric approach we focused both on the business cycle and on the growth cycle. For providing a dating for the latter, the series have been filtered from the trend component using the Hodrick-Prescott (HP) filter. ${ }^{16}$ The filtered series are reported in Figures 5 and 6 while Tables 6 and 7 show the turning points identified in the series.

The turning points of the Industrial Production growth cycle are compared with the chronology provided by the OECD, which is based on their composite leading indicator (CLI - see Arnaud (2000) and Arnaud and Hong (2001)). Note that the OECD series is referred to the euro area; no studies deal with the EU15 series. Differently, the GDP chronology is compared with the turning points identified by Harding and Pagan (2001, 2003). The two authors used the GDP series obtained by the European Central Bank (see Fagan et al. 2001). Even in this case the comparison is with the euro area series.

16 The growth cycle extraction is well known by practitioners as an intricate issue. Although the literature is very extensive on this topic, there is no clear recommendation. Anas et al. (2007) compare the Baxter-King (1999) filter, the HP filter, the Christiano-Fitzgerald (1999) filter and the "two-stages" Hodrick-Prescott filter (see Artis et al., 2003). Actually, all these filters are band-pass filters which aim at retaining unaltered the cycle stylised facts while removing high and low frequency components. Generally, the movements with a period lower than 1.5 years and greater than 6 or 8 years are disregarded in the spectral domain. These filters differ only in the way they approximate the ideal band-pass filter. As a small experience, Anas et al. (2007) compare the 4 filters on the euro aggregated IPI series. A preliminary non-parametric dating applied to each growth cycle shows that the dates of peaks and troughs are practically the same. According to this result, we prefer to use the HP filter given that it is traditionally used by National Statistical Institutes.

Other useful references on possible shortcomings of the HP filter are Ravn and Uhlig (2001), and Zarnowitz and Ozyildirim (2001). 
Table 6 Turning points - Industrial Production Index - EU15

\begin{tabular}{|c|c|c|c|c|c|}
\hline \multicolumn{2}{|c|}{ Business Cycle } & \multicolumn{2}{|c|}{ Growth Cycle } & \multicolumn{2}{|c|}{ OECD (2001) - Growth Cycle } \\
\hline TP type & Period & TP type & Period & TP type & Period \\
\hline & & Trough & 1972 January & & \\
\hline Peak & 1974 June & Peak & 1974 June & Peak & 1974 January \\
\hline \multirow[t]{3}{*}{ Trough } & 1975 July & Trough & 1975 July & Trough & 1975 July \\
\hline & & Peak & 1976 December & Peak & 1977 January \\
\hline & & Trough & 1978 April & Trough & 1978 April \\
\hline \multirow[t]{3}{*}{ Peak } & 1980 January & Peak & 1980 January & Peak & 1980 March \\
\hline & & Trough & 1980 December & & \\
\hline & & Peak & 1981 October & & \\
\hline Trough & 1982 December & Trough & 1982 December & Trough & 1982 December \\
\hline Peak & 1986 March & Peak & 1985 November & Peak & 1986 April \\
\hline Trough & 1987 January & Trough & 1987 August & Trough & 1987 January \\
\hline \multirow[t]{3}{*}{ Peak } & 1991 January & Peak & 1990 September & Peak & 1991 January \\
\hline & & Trough & 1991 April & & \\
\hline & & Peak & 1992 March & & \\
\hline \multirow[t]{5}{*}{ Trough } & 1993 June & Trough & 1993 June & Trough & 1993 July \\
\hline & & Peak & 1994 December & Peak & 1994 December \\
\hline & & Trough & 1996 November & Trough & 1996 December \\
\hline & & Peak & 1998 March & Peak & 1998 March \\
\hline & & Trough & 1999 March & Trough & 1999 May \\
\hline Peak & 2001 January & Peak & 2000 December & & \\
\hline \multirow[t]{3}{*}{ Trough } & 2001 December & Trough & 2001 December & & \\
\hline & & Peak & 2002 June & & \\
\hline & & Trough & 2003 May & & \\
\hline
\end{tabular}




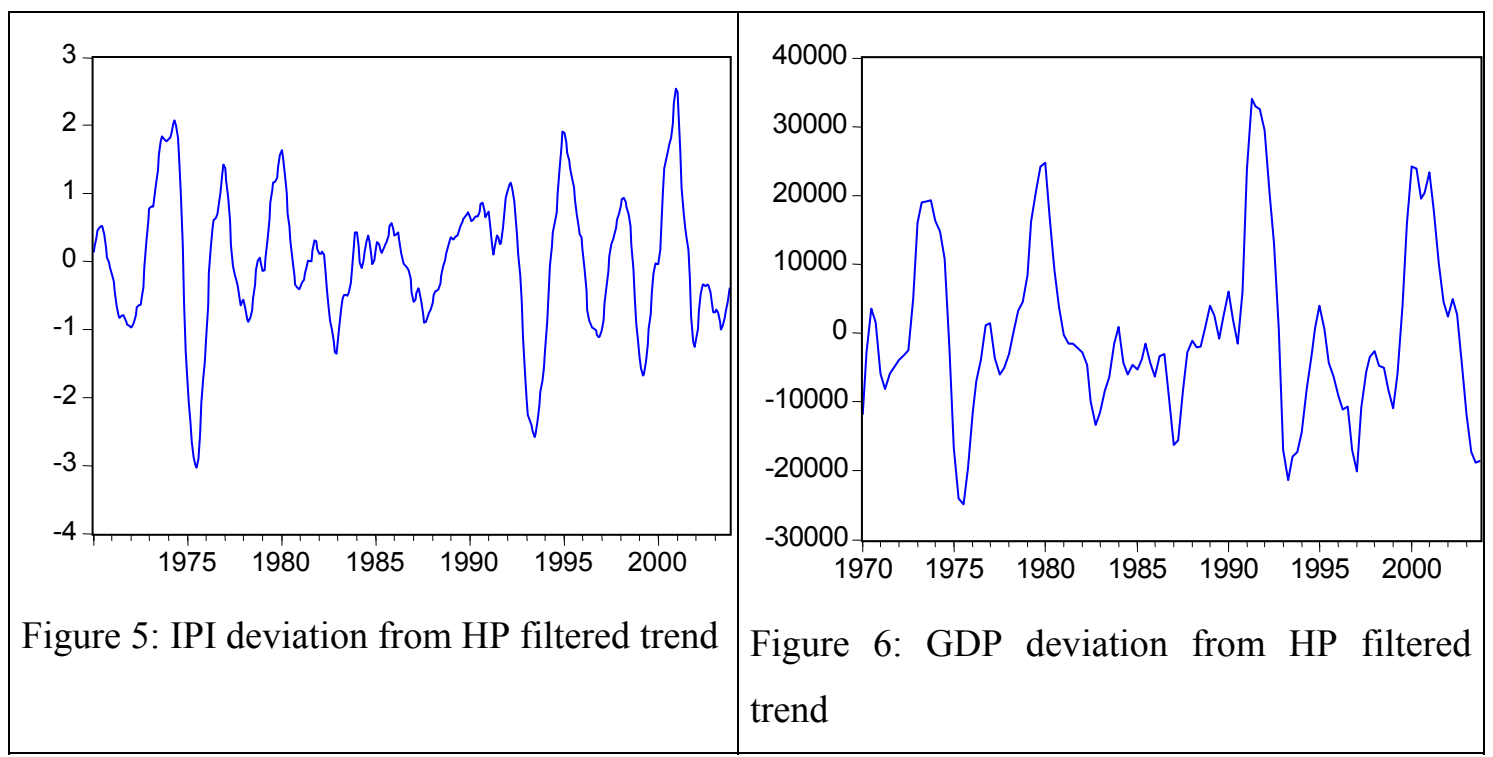

Table 6 Turning points - Gross Domestic Product - EU15

\begin{tabular}{|c|c|c|c|c|c|c|c|}
\hline \multicolumn{4}{|c|}{ Business Cycle } & \multicolumn{4}{|c|}{ Growth Cycle } \\
\hline \multicolumn{6}{|c|}{ Harding-Pagan } & \multicolumn{2}{|c|}{ Harding-Pagan } \\
\hline Type & Period & Type & Period & Type & Period & TP type & Period \\
\hline & & & & $\mathrm{T}$ & 1971 Q2 & & \\
\hline $\mathrm{P}$ & 1974 Q3 & $\mathrm{P}$ & 1974 Q3 & $\mathrm{P}$ & 1973 Q4 & $\mathrm{P}$ & 1974 Q1 \\
\hline \multirow[t]{3}{*}{$\mathrm{T}$} & 1975 Q2 & $\mathrm{T}$ & 1975 Q1 & $\mathrm{T}$ & 1975 Q3 & $\mathrm{T}$ & 1975 Q2 \\
\hline & & & & & & $\mathrm{P}$ & 1976 Q4 \\
\hline & & & & & & $\mathrm{T}$ & 1977 Q3 \\
\hline $\mathrm{P}$ & 1980 Q1 & $\mathrm{P}$ & 1980 Q1 & $\mathrm{P}$ & 1980 Q1 & $\mathrm{P}$ & 1980 Q1 \\
\hline \multirow[t]{5}{*}{$\mathrm{T}$} & 1980 Q4 & $\mathrm{T}$ & 1981 Q1 & & & & \\
\hline & & $\mathrm{P}$ & 1982 Q2 & & & & \\
\hline & & $\mathrm{T}$ & $1982 \mathrm{Q} 4$ & $\mathrm{~T}$ & 1982 Q4 & $\mathrm{T}$ & 1983 Q3 \\
\hline & & & & & & $\mathrm{P}$ & 1984 Q1 \\
\hline & & & & & & $\mathrm{T}$ & 1987 Q1 \\
\hline $\mathrm{P}$ & 1992 Q1 & $\mathrm{P}$ & 1992 Q1 & $\mathrm{P}$ & 1991 Q2 & $\mathrm{P}$ & 1990 Q1 \\
\hline \multirow[t]{6}{*}{$\mathrm{T}$} & 1993 Q1 & $\mathrm{T}$ & 1993 Q1 & $\mathrm{T}$ & 1993 Q2 & $\mathrm{T}$ & 1993 Q4 \\
\hline & & & & $\mathrm{P}$ & 1995 Q1 & $\mathrm{P}$ & 1994 Q4 \\
\hline & & & & $\mathrm{T}$ & 1997 Q1 & $\mathrm{T}$ & 1997 Q1 \\
\hline & & & & $\mathrm{P}$ & 1998 Q1 & & \\
\hline & & & & $\mathrm{T}$ & 1999 Q1 & & \\
\hline & & & & $\mathrm{P}$ & 2000 Q1 & & \\
\hline
\end{tabular}




\section{$4 \quad$ Univariate Markov Switching Dating}

The non-parametric chronology is then revised using a Markov switching intercept model with state dependent heteroskedasticity (MSIH-AR):

$$
\Delta \ln \left(y_{t}\right)=\mu\left(S_{t}\right)+\sum_{j=1}^{p} \alpha_{j}\left(S_{t}\right) \Delta \ln \left(\gamma_{t}\right)+\sigma\left(S_{t}\right) \varepsilon_{t}
$$

where $S_{t}$ is a $k$-state Markov chain. ${ }^{17}$ Following Krolzig (1997), we considered a datadriven specification of the number of regimes and of the autoregressive order. We thus started with an MSIH(4)-AR(1) for the IPI and an MSIH(3)-AR(1) for the GDP. After the selection procedure we ended up with a MSIH(4)-AR(0) for the IPI and an MSIH(2)-AR(0) for the GDP. In this case we only considered the dating of the business cycle, i.e. we used the growth rates of the Trend-Cycle components, avoiding by this approach the discussions on the appropriate detrending method as mentioned in the introduction. The model has been estimated using the Ox Package MSVAR implemented by Krolzig. ${ }^{18}$

Tables A1 to A2 and Figures A1 and A2 in the Appendix report the transition matrices, the estimated parameters and their standard errors and the smoothed regime probabilities. In the case of IPI the recession phases are identified with the Regime 1, while regimes 2 to 4 identify the expansion phases. This result could seem a bit surprising; however, in a MS framework, there is no reason to believe that with four regimes 2 of them would be referred to recession phases, as well as, there is no reason to get a recession regime with negative growth rates. This is the case for the GDP where the recession regime has a small but positive mean.

To consider 4 states in the IPI case maybe questionable, since the recession is identified with only one state. Anyhow, our choice was confirmed by the fact that the transition matrix is almost tridiagonal providing a smooth passage among regimes and the regimes can be labelled as follows: Regime 1 = Recession; Regime $2=$ Stagnation; Regime 3 = Low Expansion; Regime $4=$ High expansion. All regimes can thus be matched with a plausible economic interpretation.

The fitted models provide persistent regimes (the lowest diagonal values in the transition matrix is 0.732 for IPI) with evident state dependant variances. For both GDP and IPI series, the model correctly identifies the recession phases. To see this, for the IPI we need to collapse the four-regime Markov chain in a two-regime one: this is done by summing up the probabilities of regimes 2 to 4 . After this step, we have two Markov chains reflecting the cycle for the IPI and for the GDP, respectively. The turning points are detected as the last month (quarter) of each regime phase. The chronology derived by this approach is reported in the $2^{\text {nd }}$ and $4^{\text {th }}$ columns of Table A3.

\footnotetext{
17 It is an $\operatorname{MSIH}(k)-\operatorname{AR}(p)$ model in the Krolzig's terminology. 


\section{$5 \quad$ Dating the Business Cycle with a Bivariate Monthly Model Including GDP and IPI}

The dating obtained with the GDP and the IPI series evidences very close turning point chronologies. A question thus arises: is it possible to jointly model the two variables allowing a combined business cycle dating?

The answer would be positive if several questions are disentangled. How is it possible to handle series at different frequencies in a unique model? Are the Markov chains driving the dynamics of the two series characterised by the same structure? Alternatively, are the two Markov chains independent, correlated or is there a common Markov chain? Do we really need a bivariate system or a single equation model could be used? This Section tries to answer to some of these questions.

A first attempt considers a correlation and concordance analysis of the expansionrecession phases (or of the two state Markov chains) detected by the univariate modelling of the IPI and GDP series. Since the IPI series is more informative than the GDP one, we chose to expand the GDP Markov chain at the monthly level under the assumption that if a quarter is in the expansion phase all the months of the quarter are in the same phase. On the resulting monthly Markov chains obtained from the GDP and IPI we computed the correlation and concordance indices, which are listed in Table 7. For comparison, the table reports also the indices computed at the quarterly level; in this case the IPI Markov chain is collapsed at the quarterly level assuming that a quarter is in recession if at least two of its months are in recession.

Table 7 Markov chain comparison

\begin{tabular}{lcc}
\hline & Monthly & Quarterly \\
\hline Correlation & 0.75372 & 0.61642 \\
Concordance & 0.88889 & 0.83206 \\
\hline
\end{tabular}

The elevate values of the indices suggest that the Markov chains driving the two variables may be highly correlated or the same.

To proceed with our analysis we decided to focus on the monthly frequency. As a first comparative analysis we could estimate a MSIH-AR model on a monthly GDP series. ${ }^{19}$ Unfortunately, this series is not available but can be reconstructed. Several approaches are available: we can estimate a monthly GDP series using the quarterly data as benchmarks and the monthly IPI as a related indicator; alternatively the Denton (1971) distribution approach can be used; furthermore, we can base our series on some purely statistical approach using the results of Stram and Wei (1990); finally, we can make some strong

19 At the moment no monthly GDP series are available, however some research is underway, see Astolfi et al. (2001). 
assumptions on the data generating process. In all cases we deal with a temporal disaggregation problem.

In the last mentioned case, by assuming that the monthly residuals of the high frequency representation follow a white noise process, we can estimate the monthly GDP growth rates by simply dividing the quarterly rate by three. The assumption is rather strong and we can generalise our approach using a more advanced technique. Comparing the Denton (1971) and Stram and Wei (1990) approaches we chose the first as our reference methodology.

Finally, it is important to discuss the possibility of disaggregating the GDP using the IPI as a reference monthly indicator. We decided to avoid this approach since it could bias the results: in fact, this approach tries to replicate the IPI movements under the aggregation constraint and can generate a dependence of the GDP cycle phases on the IPI cycle phases.

We thus obtained a monthly GDP series, which is shown in Figures 7 and 8 together with the IPI series. Figure 8 evidences the concordance of the monthly growth rates except at the end of 1991.

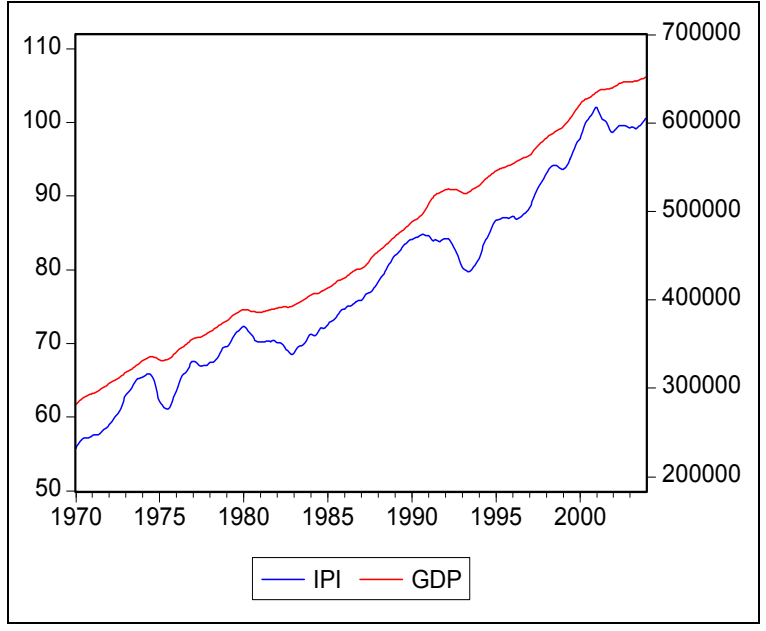

Figure 7: Monthly IPI and GDP

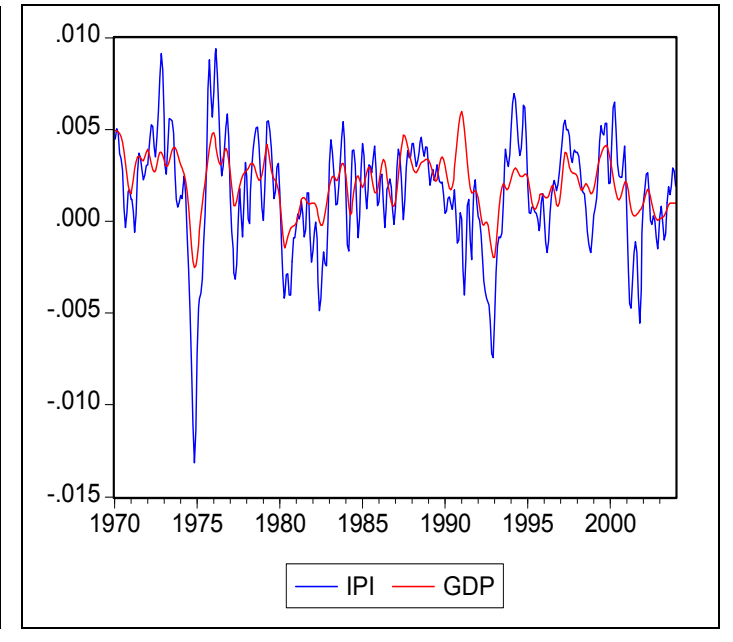

Figure 8: Growth rates

We then estimated a MSIH-AR model on the newly available monthly GDP series. The results are displayed in Figure A3 and Tables 13 and 14. Even in this case, we chose a four state Markov switching model. The regime interpretation is similar to the one used for the IPI index: recession, stagnation, expansion, and high expansion. The transition matrix is tridiagonal evidencing a smooth transition among the regimes. Regimes are also persistent and the recession phases are comparable to the IPI ones reported in Table 11.

To directly compare recessions, Figure A4 reports the smoothed probabilities of a recession for the monthly IPI and GDP series: we can note that recession phases are most of the time concordant in the two series. 
We face now a choice: should we model jointly the two series with a bivariate MSVAR model or should we focus on only one of the series? We can expect that the contemporaneous IPI level influence the monthly GDP given that the industrial sector represents one of the main components of a country product. Differently, the current IPI may not be influenced by the current GDP but from its past values, which contain information about the evolution of the investments. Therefore, we may assume the weak exogeneity of GDP for IPI and estimate a MSIH-AR model for the monthly GDP using the IPI as an explanatory variable. ${ }^{20}$

Then, we estimated this conditional model and the results are reported in Figure A5 and Tables 15 and 16, while the chronology is included in Table 11. As for the previous MS estimations we focused on a four regimes model. Results for the recession phase are comparable with the previous estimations; however, the regime persistence is affected as well as the variability among the stagnation and the expansion regimes.

To avoid excessive regime movements, we consider a more general bivariate MSIVAR model. In this case we must specify an additional assumption on the Markov chains driving the GDP and IPI series. In principle, we can assume two different Markov chains, which can be independent or correlated; alternatively, there can be a common Markov chain. Given that we are focusing on the business cycle, the assumption that it is unique directly translates on the assumption of a common Markov chain. Differently, we should focus on an MSI-VAR model driven by a Markov chain whose number of regimes is the product of the regime of the Markov chains driving each series (in our case 16, too much for obtaining consistent estimates). Results are reported in Figure A6 and Tables 17 and 18, while Table 11 reports the chronology. Figure A7 shows the smoothed probabilities of a recession for the MSI-VAR model; the recession phases are comparable to the one reported in Figure A4 and referred to univariate Markov switching models.

In particular, analysing the Figure A7 we can note that the model evidences that the end of 2003 is associated with the stagnation regime, and that the known recessions of mid 70's, beginning of 80's, 1992 and 1993, and 2002 are appropriately detected. Furthermore, Table 11 points out that we can easily identify the most severe recessions with simple models, while the comparative advantage of using a bivariate model resides in the identification of different stagnation and growth phases which, in turn, may become very useful for policy purposes.

To conclude, the proposed approach that combines monthly and quarterly series gives interesting and reliable results. We are thus able to include in a monthly chronology the information coming form the basic broad-based measure of economic activity given by the GDP, even if it is actually recorded only on a quarterly frequency for the European countries.

20 Note that the weak exogeneity requires that the joint distribution $f\left(x_{t}, y_{t} \mid x_{t-1}, \ldots, x_{1}, y_{t-1}, \ldots, y_{1} ; \lambda\right)$ can be factorised as $f\left(x_{t} \mid y_{t}, x_{t-1}, \ldots, x_{1}, y_{t-1}, \ldots, y_{1} ; \lambda_{1}\right) f\left(x_{t} \mid x_{t-1}, \ldots, x_{1}, y_{t-1}, \ldots, y_{1} ; \lambda_{2}\right)$ and that the two parameter sets $\lambda_{1}$ and $\lambda_{1}$ are variation free. We do not assume the strong exogeneity, since past GDP values may include relevant information about the evolution of investments, which, in turns, may affect the future evolution of the Industrial Production. 


\section{Concluding Remarks}

The paper addresses the issue of producing a monthly business cycle chronology for EU15 taking into account IPI and GDP data, even if they are at different frequency. The first contribution of the paper is the estimation of the relevant EU15 series back to 1970 and the construction of a monthly GDP series by using the Denton approach for temporal disaggregation. This monthly series is characterised by a cycle similar to the one describing the monthly IPI series.

We thus propose and estimate a bivariate Markov-switching model for the monthly GDP and IPI series and use it for dating the EU15 business cycle. The reference dates we provide are very close to the ones estimated on the euro area, a fact that suggests the presence of similar cycle movements across the major European countries.

The consideration of a monthly GDP series and the results of our analysis are certainly helpful in the direction of creating a real time approach for business cycle detection, which constitutes our current research purpose. Anyhow, the results could be strongly influenced by GDP revisions and thus a real time detection exercise will benefit of more reliable GDP estimates, of the inclusion of additional coincident indicators or data from a factor analysis that proxy GDP, with the benefit of being robust to revisions. 


\section{References}

Acemoglu, D. and A. Scott. 1997. "Asymmetric business cycles: Theory and time-series evidence," Journal of Monetary Economics 40:3, pp. 501-33.

Anas, J.; M. Billio, L. Ferrara and M. Lo Duca. 2007. "A turning point chronology for the Euro-zone classical and growth cycle," in Growth and Cycle in the Eurozone (eds G.L. Mazzi and G. Savio), pp. 261-274, Palgrave Macmillan.

Arnaud, B. 2000. "The OECD system of leading indicators: recent efforts to meet users needs," paper presented at the 25th CIRET Conference in Paris.

Arnaud, B. and E. P. Hong. 2001. "Comparison of compilation methodologies for the Composite Leading Indicators of Euro area," OECD (http://www.oecd.org/dataoecd/34/20/1907370.pdf).

Artis, M.,; H.M. Krolzig, and J. Toro. 2004. "The European Business Cycle," Oxford Economic Papers, 56, pp. 1-44

Artis, M.; M. Marcellino and T. Proietti. 2003. "Dating the Euro Area Business Cycle," CEPR Discussion Papers 3696.

Astolfi, R.; D. Ladiray, L. Mazzi., F. Sartori and R. Soares. 2001. "A monthly indicator of GDP for the Euro-zone," proceedings of New Techniques and Technologies for Statistics.

Baxter, M. and R. G. King. 1999. "Measuring Business Cycles: Approximate Band-Pass Filters for Economic Time Series," Review of Economics and Statistics 81:4, pp. 575-93.

Bry, G. and C. Boschan. 1971. "Cyclical analysis of time series: Selected procedures and computer programs," NBER, Technical Paper, no. 20.

Burns, A. F. and W. C. Mitchell. 1946. Measuring Business Cycles. NBER. New York: Columbia University Press.

Camacho, M.; G. Pérez-Quirós and L. Saiz. 2005. "Do European business cycles look like one?" Documentos De Trabajo 518, Banco de Espana.

Canova, F. 1994. "De-trending and Turning Points," European Economic Review 38, pp. 614-23.

Caporin, M. and D. Sartore. 2006. "Methodological aspects of time series back-calculation," Proceedings of the Workshop on frontiers in benchmarking techniques and their application to official statistics, Luxembourg, 6-7 April, Eurostat Working Paper series

Chow, G. and A. L. Lin. 1971. "Best linear unbiased interpolation, distribution and extrapolation of time series by related series," Review of Economics and Statistics 53, pp. 372-75.

Christiano, L.J. and T.J. Fitzgerald. 1999. "The band pass filter", NBER Working paper 7257.

Denton, F. T. 1971. "Adjustment of monthly or quarterly series to annual totals: an approach based on quadratic minimization," Journal of the American Statistical Association 66, pp. 99-102.

Di Fonzo, T. 2003a. "Constrained retropolation of high-frequency data using related series. A simple dynamic model approach," Statistical Methods \& Applications 12, pp. 109-19.

Di Fonzo, T. 2003b. "Temporal disaggregation of economic time series: towards a dynamic extension," European Commission (Eurostat), Working Papers and Studies. pp. 41.

Doornick, J. A. 2001. Ox: an object-oriented matrix language. New York: Timberlake Consultants Press.

Fagan, G.; G. Henry and R. Mestre. 2001. "An Area-Wide-Model (AWM) for the Euro Area," European Central Bank, Working Paper no 42.

Hamilton, J. D. 1989. "A new approach to the economic analysis of non stationary time series and the business cycle," Econometrica 57:2, pp. 357-84.

Hamilton, J. D. 1990. "Analysis of time series subject to changes in regime," Journal of Econometrics 45, pp. 39-70.

Hamilton, J. D. 1994. Time series analysis. Princeton: Princeton University Press.

Harding, D. 2002. "Non-parametric turning point detection, dating rules and the construction of the Eurozone chronology," paper presented at the Eurostat Colloquium on modern tools for business cycle analysis in Luxembourg, November 2002.

Harding, D. and A. Pagan A. 2001. "Extracting, analysing and using cyclical information," mimeo, University of Melbourne.

Harding, D. and A. Pagan. 2003. "A comparison of two business cycle dating methods," Journal of Economic Dynamics and Control 27:9, pp.1681-90. 
Harding, D. and A. Pagan. 2002. "Dissecting the Cycle: A Methodological Investigation," Journal of Monetary Economics 49:2, pp. 365-81.

Kaufmann, S. 2003. "The Business Cycle of European Countries: Bayesian Clustering of CountryIndividual IP Growth Series," Oesterreichesche Nationalbank, Working Paper No. 83.

Krolzig, H. M. 1997. Markov-Switching vector auto-regressions. Modelling, statistical inference and applications to business cycle analysis. Berlin: Springer.

Krolzig, H. M. 1998. Econometric Modelling of Markov Switching Vector Autoregression using MSVAR for Ox. Oxford: Department of Economics, University of Oxford.

McAdam, P. 2003. "US, Japan and the Euro Area: comparing business cycle features," European Central Bank, Working Paper no. 283.

Neftçi, S. N. 1984. "Are economic time series asymmetric over the business cycle?" Journal of Political Economy 92, pp. 307-28.

Proietti, T. 1998. "Characterizing Asymmetries in Business Cycles Using Smooth-Transition Structural Time-Series Models," Studies in Nonlinear Dynamics \& Econometrics 3:3, Article 2.

Ramsey, J. B. and P. Rothman. 1996. "Time irreversibility and business cycle asymmetry," Journal of Money, Credit and Banking 28, pp. 3-20.

Ravn, M.O. and H. Uhlig. 2001. "On Adjusting the HP-Filter for the Frequency of Observations," CEPR Discussion Papers No. 2858.

Sichel, D. E. 1993. "Business Cycle Asymmetry: A Deeper Look," Economic Inquiry XXXI, pp. 224-36.

Stram, D. O. and W. W. S. Wei. 1990. "Disaggregation of time series models," Journal of the Royal Statistical Society 52, pp. 453-67.

Zarnowitz, V. and A. Ozyildirim. 2002. "Time Series Decomposition and Measurement of Business Cycles, Trends and Growth Cycles," NBER Working Paper No. 8736. 


\section{Appendix}

Figure A1 Industrial Production Index: 4 regimes Markov switching intercept model - fitted values and smoothed probabilities

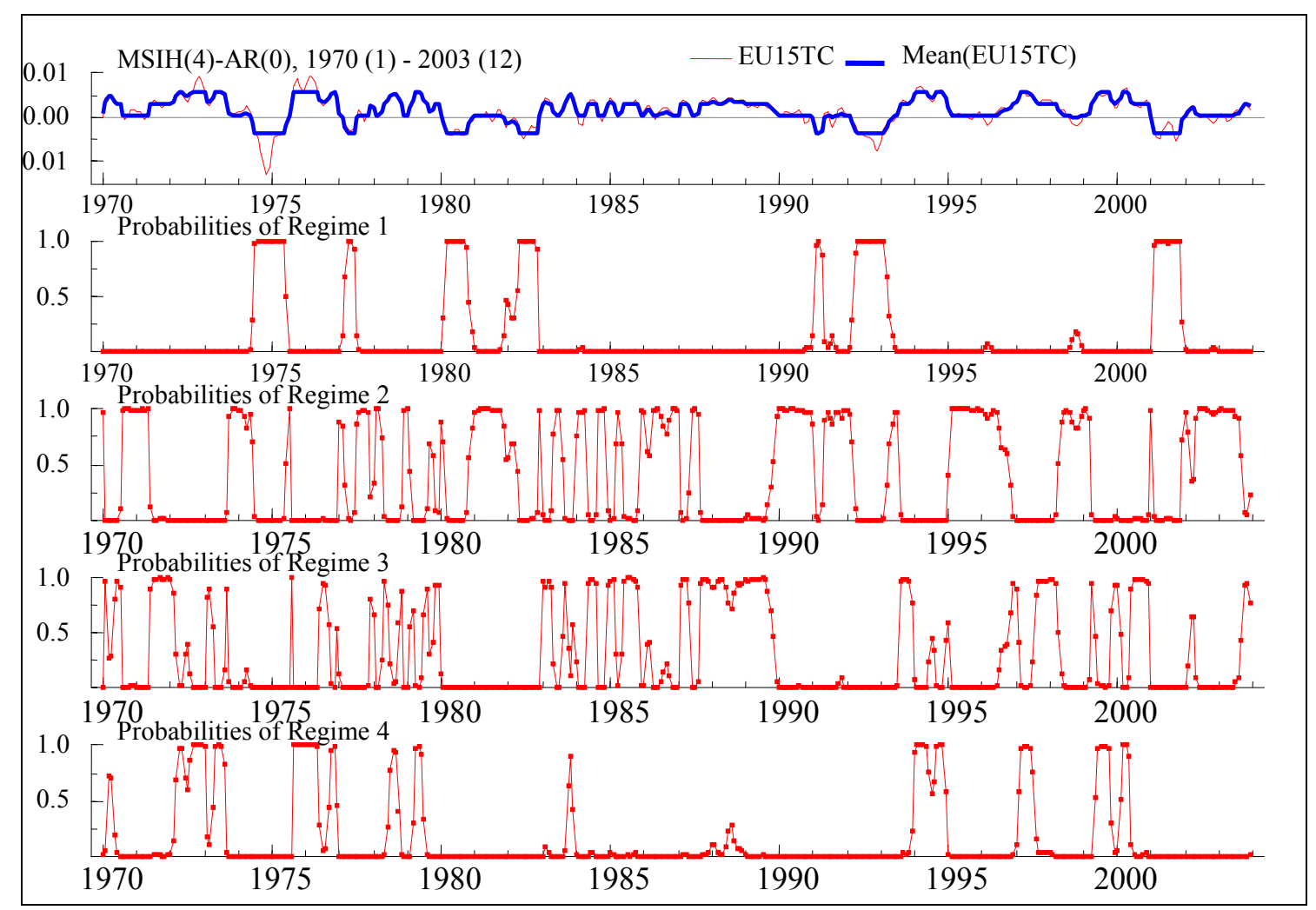

Table A1 Transition Matrix

\begin{tabular}{lcccc}
\hline & Regime 1 & Regime 2 & Regime 3 & Regime 4 \\
\hline Regime 1 & 0.867 & 0.133 & - & - \\
Regime 2 & 0.047 & 0.831 & 0.121 & 0.001 \\
Regime 3 & - & 0.152 & 0.732 & 0.116 \\
Regime 4 & - & 0.016 & 0.196 & 0.788 \\
\hline Missing probability estimates are equal to zero. & & & \\
\hline
\end{tabular}


Table A2 Estimated Coefficients

\begin{tabular}{clllcl}
\hline Mean & Coefficient & \multicolumn{1}{c}{ Standard. Err. } & T-stat. & St. Deviation & Coefficient \\
\hline$\mu_{1}$ & -0.0038 & 0.0004 & -9.202 & $\sigma_{1}$ & 0.00249 \\
$\mu_{2}$ & 0.0005 & 0.0001 & 3.410 & $\sigma_{2}$ & 0.00108 \\
$\mu_{3}$ & 0.0032 & 0.0002 & 21.045 & $\sigma_{3}$ & 0.00077 \\
$\mu_{4}$ & 0.0055 & 0.0003 & 21.601 & $\sigma_{4}$ & 0.00139 \\
\hline
\end{tabular}

Log-Likelihood: 2010.895

Figure A2 Gross Domestic Product: 2 regimes Markov switching intercept model fitted values and smoothed probabilities

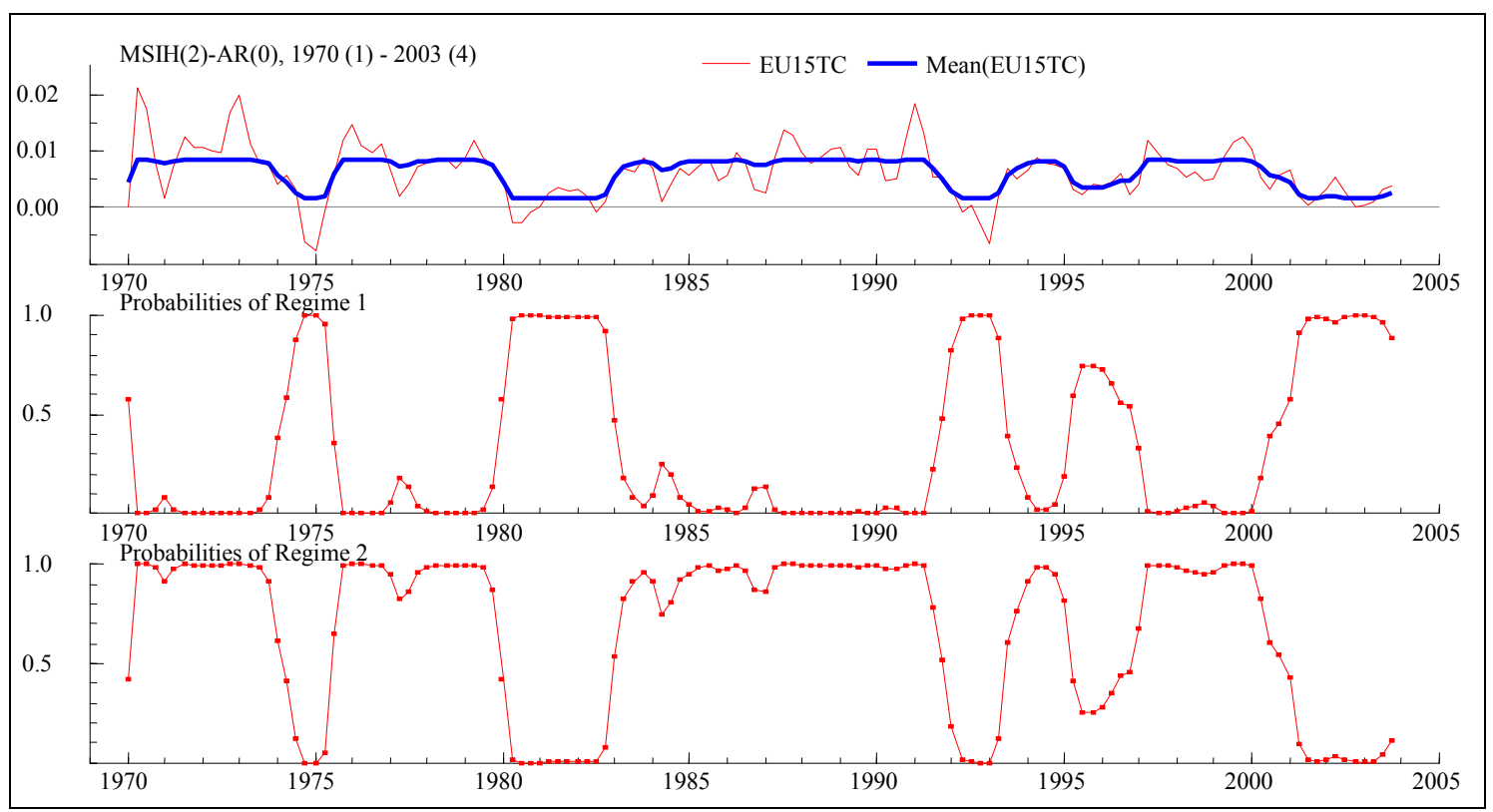

Table A3 Transition Matrix

\begin{tabular}{lcc}
\hline & Regime 1 & Regime 2 \\
\hline Regime 1 & 0.865 & 0.135 \\
Regime 2 & 0.069 & 0.931 \\
\hline
\end{tabular}


Table A4 Estimated Coefficients

\begin{tabular}{cllccc}
\hline Mean & Coefficient & \multicolumn{1}{c}{ Standard. Err. } & T-stat. & St. Deviation & Coefficient \\
\hline$\mu_{1}$ & 0.0016 & 0.0008 & 2.022 & $\sigma_{1}$ & 0.00335 \\
$\mu_{2}$ & 0.0083 & 0.0005 & 14.837 & $\sigma_{2}$ & 0.00381 \\
\hline Log-Likelihood: 550.161 & & & \\
\hline
\end{tabular}

Figure A3 Smoothed probabilities of a recession - comparison of the IPI and GDP results

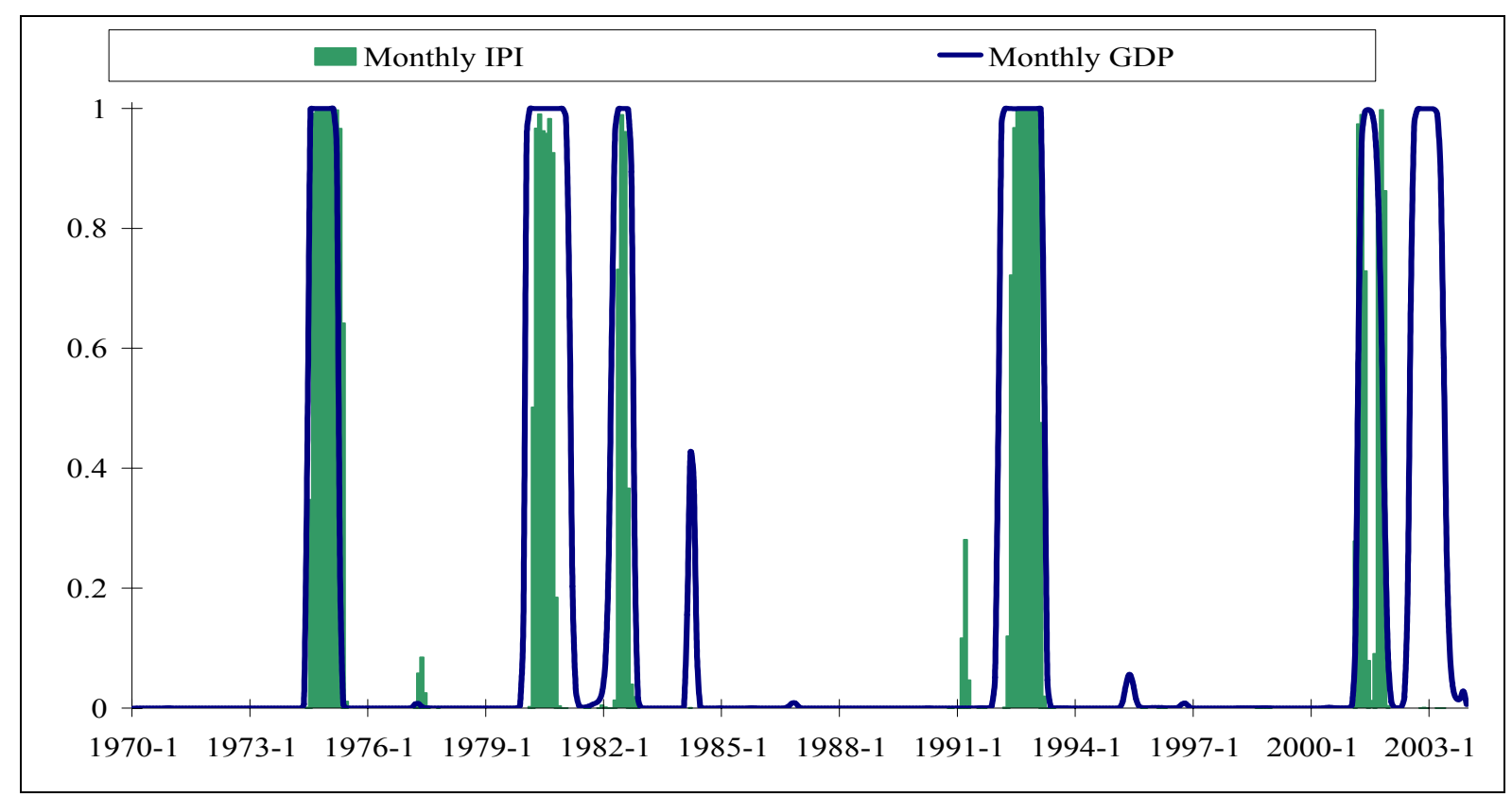


Table A5 Business Cycle Chronology

\begin{tabular}{|c|c|c|c|c|c|c|c|}
\hline $\begin{array}{c}\text { Model } \\
\text { Explanatory } \\
\text { Recession }\end{array}$ & NP IPI & NP GDP & M IPI (4) & Q GDP (2) & M GDP (4) & $\begin{array}{l}\text { M GDP (4) } \\
\text { M IPI } \\
\text { Regime } 1\end{array}$ & Regime 1 \\
\hline \multicolumn{4}{|l|}{ Trough } & \multicolumn{4}{|l|}{$1970-3^{* *}$} \\
\hline Peak & $1974-6$ & $1974-9$ & $1974-7$ & $1974-3$ & $1974-3$ & $1974-8$ & $1974-6$ \\
\hline Trough & $1975-7$ & $1975-6$ & $1975-5$ & $1975-6$ & $1975-4$ & $1975-3$ & $1975-4$ \\
\hline Peak & 1980-1 & $1980-3$ & $1980-2$ & $1979-12$ & 1980-1 & $1979-12$ & 1980-1 \\
\hline Trough & & $1980-12$ & $1980-9$ & & 1981-3 & $1981-4$ & $1981-3$ \\
\hline Peak & & & $1982-4 *$ & & $1982-3$ & $1982-7^{*}$ & $1982-3$ \\
\hline Trough & $1982-12$ & & $1982-7^{*}$ & $1982-12$ & $1982-10$ & $1982-9 *$ & $1982-10$ \\
\hline Peak & $1986-3$ & & & & & & \\
\hline Trough & $1987-1$ & & & & & & \\
\hline Peak & 1991-1 & $1992-3$ & $1992-4$ & 1991-12 & $1992-2$ & $1992-1$ & $1992-2$ \\
\hline Trough & $1993-6$ & 1993-3 & 1993-1 & $1993-6$ & 1993-4 & $1993-4$ & $1993-4$ \\
\hline Peak & & & & 1996-12 & & & \\
\hline Trough & & & & 2000-12 & & & \\
\hline Peak & 2001-1 & & $2001-2^{*}$ & & 2001-3 & & 2001-3 \\
\hline Trough & & & $2001-5^{*}$ & & & & \\
\hline Peak & & & $2001-8^{*}$ & & & & \\
\hline Trough & $2001-12$ & & $2001-11^{*}$ & & 2001-11 & & 2001-11 \\
\hline Peak & & & & & $2002-7$ & $2002-8$ & $2002-7$ \\
\hline \multicolumn{2}{|l|}{ Trough } & & & & $2003-6$ & & 2003-5 \\
\hline \multicolumn{8}{|c|}{ * $\quad$ Turning points that would be deleted imposing a minimum duration of at least 7 months } \\
\hline \multicolumn{8}{|c|}{$\begin{array}{l}\text { Turning points too close to sample boarders (unreliable or subject to possible effects of the revision process of official } \\
\text { statistics) }\end{array}$} \\
\hline
\end{tabular}


Figure A4 Monthly Gross Domestic Product: 4 regimes Markov switching intercept model - fitted values and smoothed probabilities

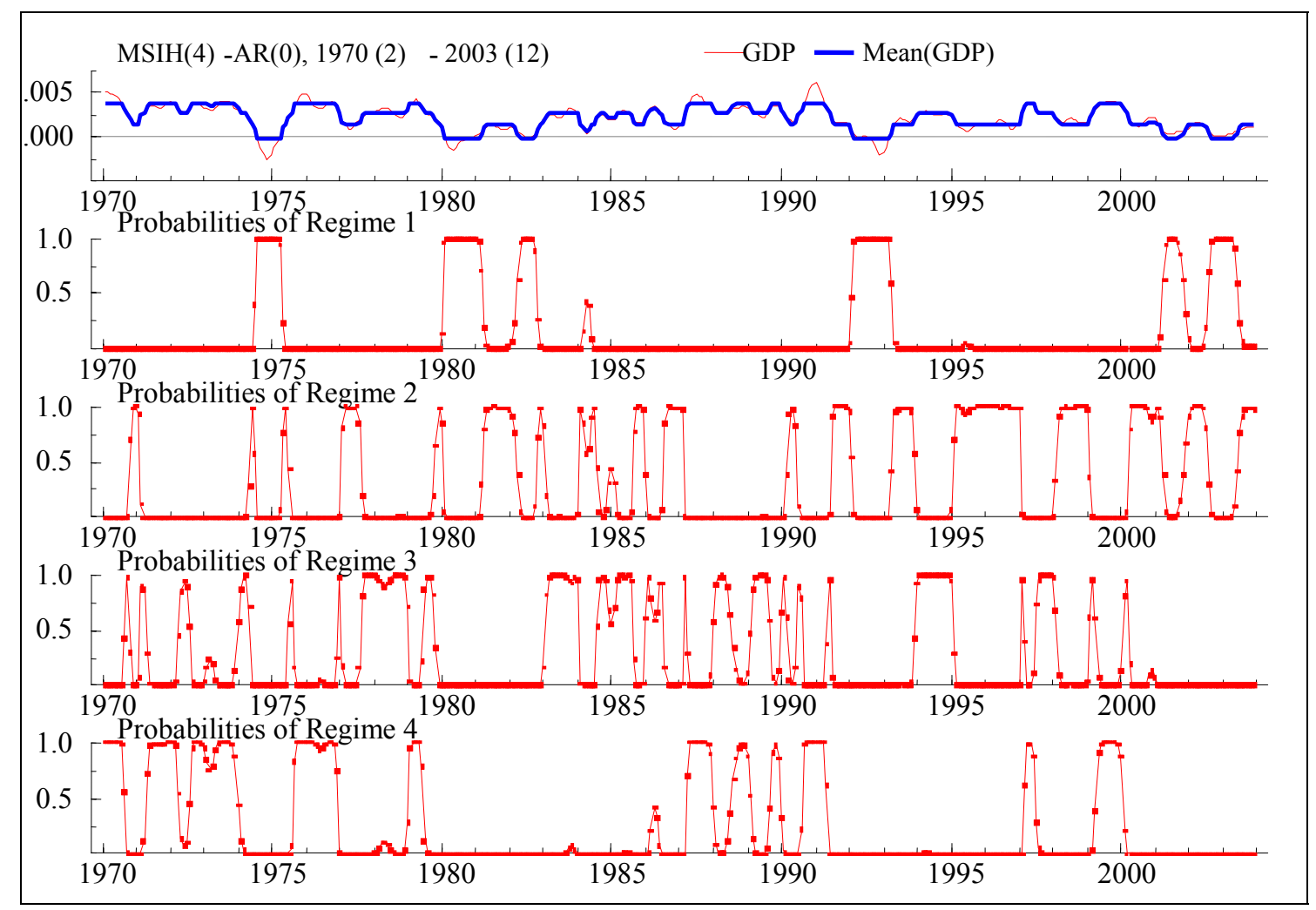

Table A6 Transition Matrix

\begin{tabular}{lcccc}
\hline & Regime 1 & Regime 2 & Regime 3 & Regime 4 \\
\hline Regime 1 & 0.897 & 0.103 & - & - \\
Regime 2 & 0.052 & 0.857 & 0.091 & - \\
Regime 3 & - & 0.113 & 0.787 & 0.100 \\
Regime 4 & - & - & 0.123 & 0.877 \\
\hline
\end{tabular}

Missing probability estimates are equal to zero. 
Table A7 Estimated Coefficients

\begin{tabular}{clllcc}
\hline Mean & Coefficient & \multicolumn{1}{c}{ Standard. Err. } & T-stat. & St. Deviation & Coefficient \\
\hline$\mu_{1}$ & -0.00027 & -0.00027 & -1.981 & $\sigma_{1}$ & 0.00087 \\
$\mu_{2}$ & 0.00141 & 0.00001 & 24.827 & $\sigma_{2}$ & 0.00043 \\
$\mu_{3}$ & 0.00261 & 0.00003 & 40.736 & $\sigma_{3}$ & 0.00034 \\
$\mu_{4}$ & 0.00380 & 0.00004 & 42.804 & $\sigma_{4}$ & 0.00065 \\
\hline Log-Likelihood: 2380.196 & & & &
\end{tabular}

Log-Likelihood: 2380.196

Figure A5 Monthly Gross Domestic Product: 4 regimes Markov switching intercept model with exogenous explanatory variable (IPI) fitted values and smoothed probabilities

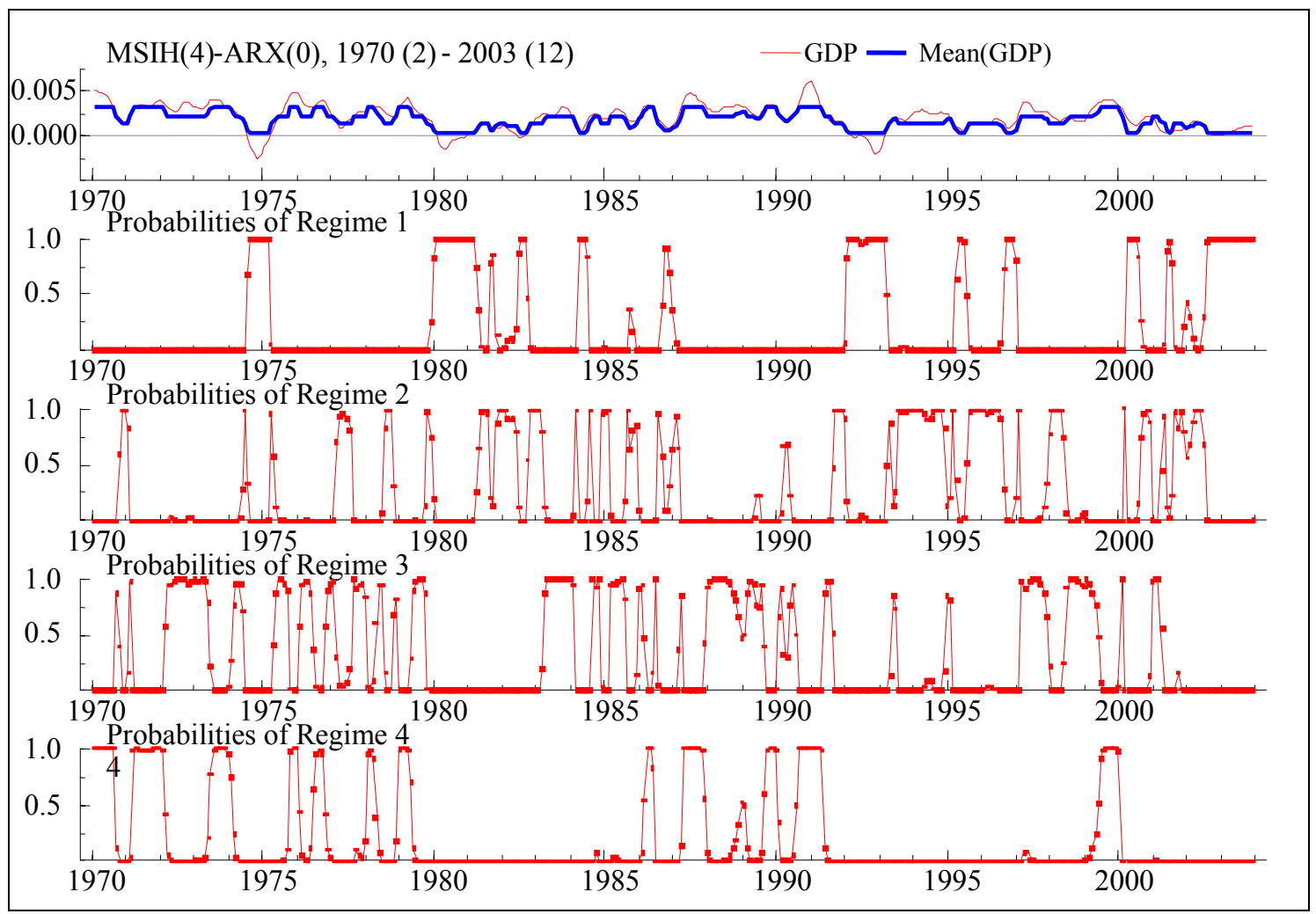


Table A8 Transition Matrix

\begin{tabular}{lcccc}
\hline & Regime 1 & Regime 2 & Regime 3 & Regime 4 \\
\hline Regime 1 & 0.860 & 0.140 & - & - \\
Regime 2 & 0.119 & 0.740 & 0.141 & - \\
Regime 3 & - & 0.128 & 0.777 & 0.095 \\
Regime 4 & - & - & 0.164 & 0.836 \\
\hline Missing probability estimates are equal to zero. & & & \\
\hline
\end{tabular}

Table A9 Estimated Coefficients

\begin{tabular}{clllcl}
\hline Mean & \multicolumn{1}{c}{ Coefficient } & \multicolumn{1}{c}{ Standard. Err. } & T-stat. & St. Deviation & Coefficient \\
\hline$\mu_{1}$ & 0.00038 & 0.00006 & 6.406 & $\sigma_{1}$ & 0.00040 \\
$\mu_{2}$ & 0.00129 & 0.00006 & 22.318 & $\sigma_{2}$ & 0.00026 \\
$\mu_{3}$ & 0.00206 & 0.00005 & 40.336 & $\sigma_{3}$ & 0.00027 \\
$\mu_{4}$ & 0.00329 & 0.00012 & 28.021 & $\sigma_{4}$ & 0.00084 \\
Dlog(IPI) & 0.22447 & 0.00926 & 24.238 & & \\
\hline
\end{tabular}

Log-Likelihood: 2467.691 
FigureA6 Bivariate MSI-VAR model for monthly GDP and IPI

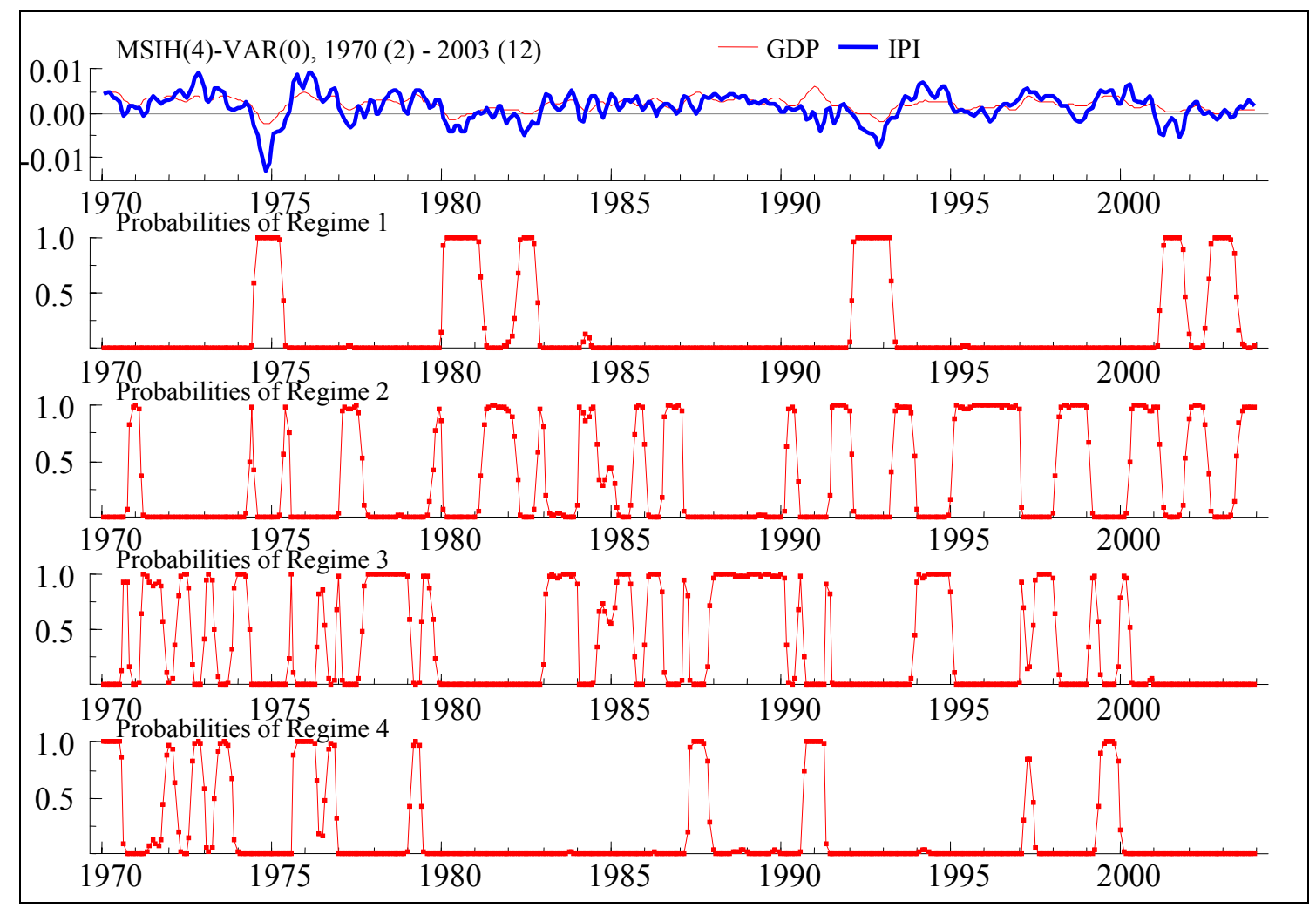

Table A10 Transition Matrix

\begin{tabular}{lcccc}
\hline & Regime 1 & Regime 2 & Regime 3 & Regime 4 \\
\hline Regime 1 & 0.903 & 0.097 & - & - \\
Regime 2 & 0.047 & 0.867 & 0.086 & - \\
Regime 3 & - & 0.087 & 0.841 & 0.072 \\
Regime 4 & - & - & 0.171 & 0.829 \\
\hline Missing probability estimates are equal to zero. & & & \\
\hline
\end{tabular}


Table A11 Estimated Coefficients

\begin{tabular}{cccccc}
\hline Mean & Coefficient & Standard. Err. & St. Deviation & GDP & Coefficient \\
\hline$\mu_{1}$ & -0.00025 & -0.00312 & $\sigma_{1}$ & 0.00087 & 0.00287 \\
$\mu_{2}$ & 0.00144 & 0.00093 & $\sigma_{2}$ & 0.00045 & 0.00181 \\
$\mu_{3}$ & 0.00278 & 0.00291 & $\sigma_{3}$ & 0.00041 & 0.00170 \\
$\mu_{4}$ & 0.00409 & 0.00392 & $\sigma_{4}$ & 0.00062 & 0.00288 \\
\hline
\end{tabular}

Log-Likelihood: 4350.115

Figure A7 Smoothed probabilities of a recession for the bivariate MS-VAR on monthly data

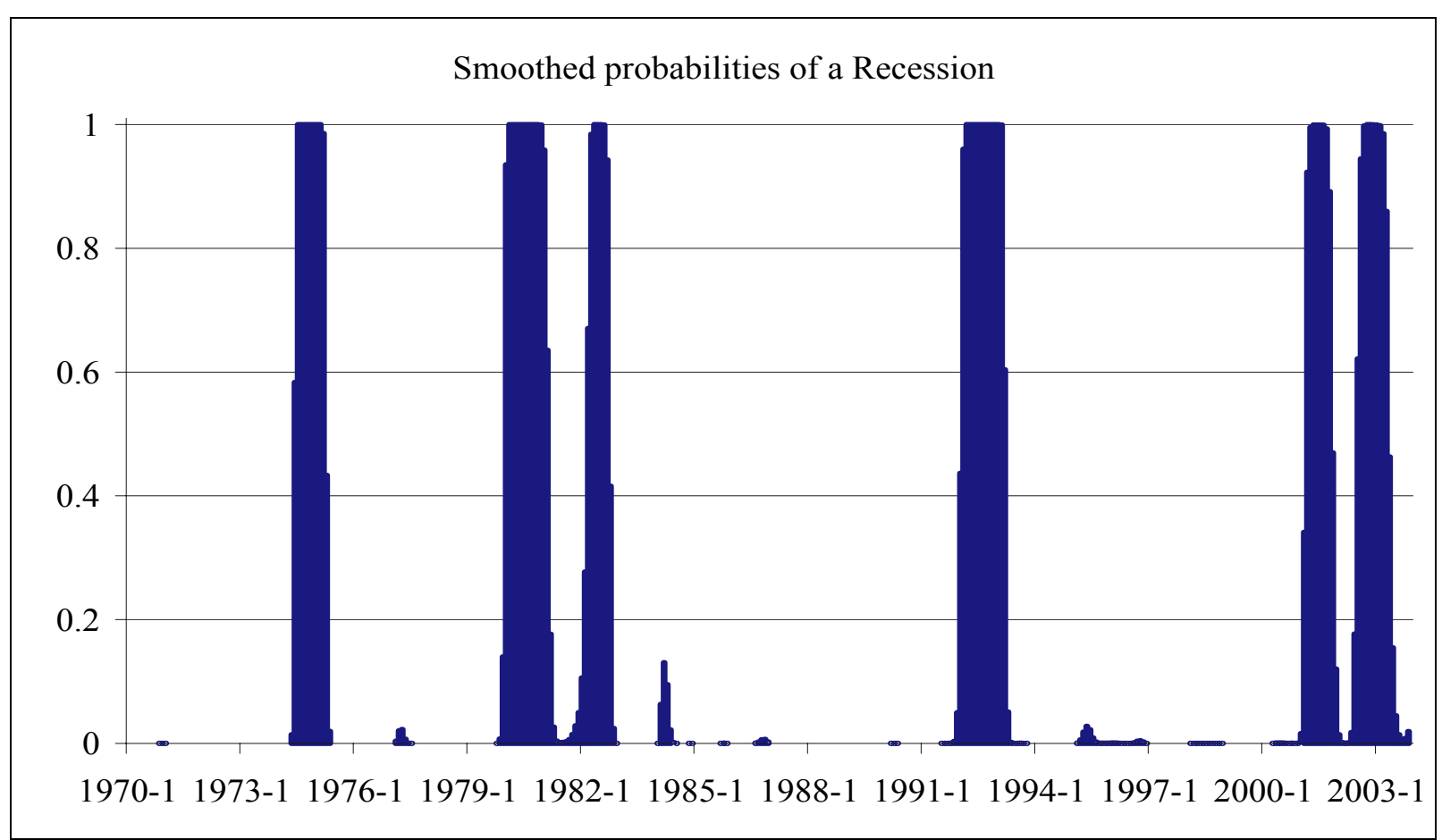

